\title{
Enhancing Methane Aromatization Performance by Reducing the Particle Size of Molybdenum Oxide
}

\author{
Jing $\mathrm{Hu}^{1,2,3}$, Jinghai Liu ${ }^{1,2}$, Jinglin Liu ${ }^{1}$, Yangyang $\mathrm{Li}^{1}$, Peihe $\mathrm{Li}^{2}$, Yin Wang ${ }^{2}$, Jingqi Guan ${ }^{3, *(1)}$ \\ and Qiubin Kan ${ }^{3, *}$ \\ 1 College of Chemistry and Materials Science, Inner Mongolia University for Nationalities, \\ Tongliao 028000, China; hwhujing@163.com (J.H.); Jhliu2008@sinano.ac.cn (J.L.); Jlliu2000@126.com (J.L.); \\ 15114714255@163.com (Y.L.) \\ 2 Inner Mongolia Key Laboratory of Carbon Nanomaterials, Nano Innovation Institute (NII), Inner Mongolia \\ University for Nationalities, Tongliao 028000, China; phli2018@foxmail.com (P.L.); Wy19890703@126.com (Y.W.) \\ 3 Institute of Physical Chemistry, College of Chemistry, Jilin University, Changchun 130023, China \\ * Correspondence: guanjq@jlu.edu.cn (J.G.); qkan@jlu.edu.cn (Q.K.)
}

Received: 11 September 2020; Accepted: 2 October 2020; Published: 9 October 2020

\begin{abstract}
Efficient use of natural gas to produce aromatics is an attractive subject; the process requires catalysts that possess high-performance active sites to activate stable $\mathrm{C}-\mathrm{H}$ bonds. Here, we report a facile synthetic strategy to modify HMCM-49 with small molybdenum oxide nanoparticles. Due to the higher sublimability of nano- $\mathrm{MoO}_{3}$ particles than commercial $\mathrm{MoO}_{3}$, they more easily enter into the channels of HMCM-49 and associate with Brønsted acid sites to form active $\mathrm{MoC}_{\mathrm{x}}$-type species under calcination and reaction conditions. Compared with commercial $\mathrm{MoO}_{3}$ modified MCM-49, nano- $\mathrm{MoO}_{3}$ modified MCM-49 exhibits higher methane conversion (13.2\%), higher aromatics yield $(9.1 \%)$, and better stability for the methane aromatization reaction.
\end{abstract}

Keywords: molybdenum oxide; methane aromatization; HMCM-49; aromatics

\section{Introduction}

The ongoing discovery of cheap natural gas has stimulated increased interest in converting the main component, methane, to higher value-added fuels and chemicals [1]. The commercial processes through which methane is converted into a mixture of carbon monoxide and hydrogen (syngas) include steam reforming, dry reforming, auto-thermal reforming, and partial reforming [2,3]. However, converting methane into liquid fuel through an indirect catalytic method is challenging. A direct, economical process of methane dehydro-aromatization (MDA) could better use these resources. MDA is therefore a promising method that has received extensive attention in the last few decades [4].

The MDA of molybdenum-modified HZSM-5 has attracted researchers' attention since Wang et al. first reported on it in 1993 [5]. The HZSM-5 zeolite was considered as one of the best carriers [6,7] and molybdenum was the optimal loading component for MDA [8-10]. However, $\mathrm{CH}_{4}$ possesses high $\mathrm{C}-\mathrm{H}$ bond strength $\left(434 \mathrm{~kJ} \cdot \mathrm{mol}^{-1}\right)$, resulting in an extremely low equilibrium for methane conversion $\left(\sim 12 \%\right.$ at $\left.700{ }^{\circ} \mathrm{C}\right)$, high coke deposition, and severe deactivation caused by Mo loss at high temperatures [11]. Seeking catalysts with high catalytic activity and stability for this reaction therefore remains a significant challenge.

Mo-based MDA catalysts are usually prepared by mechanical mixing, leading to the dispersion of Mo(VI)-oxo species on the outside surface of the zeolite and inside the microporous channel of the zeolite through high-temperature treatment. The Mo species react with acidic protons to form $\left[\mathrm{MoO}_{2}\right]^{2+}$ monomers and $\left[\mathrm{Mo}_{2} \mathrm{O}_{5}\right]^{2+}$ dimers [12]. The dispersion of $\mathrm{MoO}_{\mathrm{x}}$ species has significant influence on the Mo content in the zeolite channel. A portion of Mo species is converted to oxide aggregates at 
high Mo loadings [13]. Mo-oxo species are reduced to $\mathrm{MoC}_{\mathrm{x}} \mathrm{O}_{\mathrm{y}}$ species during the induction period of the reaction and then fully carburized into a $\mathrm{MoC}_{\mathrm{x}}$-type phase during the reaction procedure, which is located in the micropore channel and at the external surface of the zeolite [9]. It is universally acknowledged that the $\mathrm{MoC}_{\mathrm{x}}$-type phase is the active center for methane non-oxidative aromatization, as revealed by XPS [14], $\mathrm{CH}_{4}$-TPSR (temperature programmed surface reaction) [15], ${ }^{95}$ Mo MAS (magic-angle spinning) NMR [16], and EXAFS (extended x-ray absorption fine structure) [17].

Many strategies have been adopted to reduce carbon deposition on active sites by improving the dispersion of Mo species. Better Mo species dispersion leads to less coking. Vollmer et al. demonstrated that zeolite topology has a strong influence on MDA activity and selectivity [18]. Zeolites with a 10-MR structure that closely resemble ZSM-5 show high MDA performance due to comparable channel dimensions. Zeolites (e.g., MCM-22 [19], MCM-49 [20], and TNU-9 [21]) exhibit similar or better catalytic activity and selectivity with benzene than the ZSM-5 zeolite. Zeolites with MWW topology possess three complex independent channel systems: 12-ring cups (half supercages $7.1 \times 7.1 \times 9.1 \AA$ ) on the external surface, an interlayer with 12-ring supercages (7.1 $\AA$ outside diameter $\times 18.2 \AA$ height) through 10-ring opening windows $(4.1 \times 5.4 \AA$ and $4.1 \times 5.9 \AA)$, and an intralayer with 2D sinusoidal 10-ring pores $(4.1 \times 5.4 \AA)$. The dispersion of active centers in different pore systems of MWW zeolites, which are solid acidic catalysts, depends on the accessibility of the acid sites, diffusion lengths, and reaction spaces for the transition state, which will affect the catalytic performance of MDA [22].

With the rapid development of nanotechnology, the nanostructure of transition-metal oxides has attracted great attention due to its exceptional potential for catalytic applications [23-25]. Molybdenum trioxide $\left(\mathrm{MoO}_{3}\right)$ is a promising material for energy storage [26], field emission [27], catalysis [28-32], etc. For example, subnano- $\mathrm{MoO}_{3}$ clusters coordinating with amino-functionalized silica exhibit excellent catalytic performance in oxidative desulfurization [33]. A single-site Mo-containing nanosized ZSM-5 zeolite with homogenous dispersion of Mo atoms shows superior catalytic activity and stability [28]. In this study, we investigated the activity of nano- $\mathrm{MoO}_{3}$-modified $\mathrm{HMCM}-49$ in MDA. We found that nano- $\mathrm{MoO}_{3}$-doped $\mathrm{HMCM}-49$ showed higher methane conversion, higher benzene yield, and better stability than commercial $\mathrm{MoO}_{3}$-modified HMCM-49.

\section{Materials and Methods}

\subsection{Catalyst Preparation}

\subsubsection{Synthesis of $\mathrm{MoO}_{3}$ Nanoparticles}

$\mathrm{MoO}_{3}$ nanoparticles were synthesized as follows: $2 \mathrm{~g}$ of ammonium heptamolybdate tetrahydrate ( $\geq 99.0 \%$, Sigma-Aldrich, Saint Louis, MO, USA) was dissolved in a $50 \mathrm{~mL}$ mixture of $\mathrm{H}_{2} \mathrm{O}$ and ethanol. An amount of $0.5 \mathrm{~g}$ of polyethylene glycol (PEG-2000, Alfa Aeser, Royston, UK) was then added to the mixture and stirred for $2 \mathrm{~h}$. After the $\mathrm{pH}$ value was adjusted to 4.5 with an $\mathrm{HNO}_{3}(65.0 \sim 68.0 \%$, analytic reagent, Damao Chemical Reagent Factory, Tianjin, China) solution, the mixture was transferred to a Teflon-lined stainless autoclave and heated at $110^{\circ} \mathrm{C}$ for $24 \mathrm{~h}$. The sediment was filtrated, washed with $\mathrm{H}_{2} \mathrm{O}$, and dried overnight in a vacuum oven at $80^{\circ} \mathrm{C}$ to obtain nano- $\mathrm{MoO}_{3}$, which was designated as $\mathrm{MoO}_{3}(\mathrm{~N})$.

\subsubsection{Synthesis of HMCM-49 Zeolites}

The MCM-49 zeolites were prepared with a hydrothermal synthesis method using hexamethyleneimine (HMI, 99\%, Sigma-Aldrich, Saint Louis, MI, USA) as the template and silica gel (AS- $40, \mathrm{SiO}_{2}: 40 \mathrm{wt} \%$, Sigma-Aldrich, Saint Louis, USA) as the silica source [34]. The original slurry was obtained by stirring a mixture of sodium aluminate $\left(\mathrm{NaAlO}_{2}, \mathrm{Al}_{2} \mathrm{O}_{3}:>45 \%\right.$, Sigma-Aldrich, Saint Louis, USA), sodium hydroxide ( $\geq 98 \%$, Sigma-Aldrich, Saint Louis, MI, USA), HMI, silica gel, and water. The molar ratio of the gel composition was $\mathrm{SiO}_{2}: 0.02, \mathrm{Al}_{2} \mathrm{O}_{3}: 0.35$, and $\mathrm{HMI}: 25 \mathrm{H}_{2} \mathrm{O}$. The reaction mixture was crystallized at $170{ }^{\circ} \mathrm{C}$ with a rotating rate of $60 \mathrm{rpm}$ for $3 \mathrm{~d}$. The resulting solid was filtrated, washed with distilled water, 
and dried overnight in an oven at $60{ }^{\circ} \mathrm{C}$. The MCM-49 precursor was dispersed with a 30 wt $\% \mathrm{H}_{2} \mathrm{O}_{2}$ solution (analytical grade, Damao Chemical Reagent Factory, Tianjin, China) in a round-bottomed flask at $90{ }^{\circ} \mathrm{C}$ for $12 \mathrm{~h}$ and then filtered and dried under ambient conditions. The HMCM-49 zeolites were obtained twice after an ion exchange with $1 \mathrm{M} \mathrm{NH}_{4} \mathrm{NO}_{3}$ (analytical grade, Damao Chemical Reagent Factory, Tianjin, China) aqueous solution at $90^{\circ} \mathrm{C}$ for $6 \mathrm{~h}$ followed by calcination in a muffle furnace at $500{ }^{\circ} \mathrm{C}$ for $8 \mathrm{~h}$.

\subsubsection{Synthesis of Mo/HMCM-49}

Mo-species-modified HMCM-49 was prepared as follows: commercial $\mathrm{MoO}_{3}(\geq 99.5 \%$, Sigma-Aldrich, Saint Louis, MI, USA, marked as $\mathrm{MoO}_{3}(\mathrm{C})$ ) and $\mathrm{MoO}_{3}(\mathrm{~N})$ were mechanically mixed with HMCM-49 to prepare Mo/HMCM-49 containing 2-8 wt \% $\mathrm{MoO}_{3}$, which was then calcined in air at $500{ }^{\circ} \mathrm{C}$ for $5 \mathrm{~h}$ to obtain Mo(C)-HMCM-49 and Mo(N)-HMCM-49.

\subsection{Catalyst Characterization}

The samples were measured with an XRD-6000 diffractometer with $\mathrm{Cu}-\mathrm{K} \alpha$ radiation (Shimadzu Corporation, Kyoto, Japan). The textural properties of the catalysts were measured by $\mathrm{N}_{2}$ physisorption at $-196{ }^{\circ} \mathrm{C}$ on ASAP-2000 equipment (Micromeritics, Atlanta, GA, USA). The SEM image was obtained with an FESEM XL-30 field emission scanning electron microscope (Hitachi Corporation, Tokyo, Japan). EDS mappings were performed with an FEI Tecnai G2 F30 STWIN field emission transmission electron microscope (FEI corporation, Eindhoven, Netherlands). $\mathrm{NH}_{3}$-TPD was carried out to estimate the acid strength distribution measured by the desorption of ammonia from 100 to $600{ }^{\circ} \mathrm{C}$ at a heating rate of $10^{\circ} \mathrm{C} / \mathrm{min}$. IR spectroscopy of pyridine adsorption was also performed to measure the acid content. All samples were activated in a form of self-supporting wafers at $200{ }^{\circ} \mathrm{C}$ under vacuum for 30 min prior to pyridine adsorption. After fully adsorbing pyridine for $1 \mathrm{~h}$ at $100^{\circ} \mathrm{C}$, the sample was outgassed in situ under vacuum at $100{ }^{\circ} \mathrm{C}$ for $1 \mathrm{~h}$ to physically remove the adsorbed pyridine. Thermogravimetric analysis was conducted with a Shimadzu DTG-60 (Shimadzu Corporation, Kyoto, Japan). The samples were heated to $800^{\circ} \mathrm{C}$ at a rate of $5^{\circ} \mathrm{C} / \mathrm{min}$ in a dry-air atmosphere.

\subsection{Catalytic Test}

The $\mathrm{MoO}_{3} / \mathrm{HMCM}-49$ catalysts were evaluated for methane non-oxidative aromatization in a continuous flow fixed-bed quartz reactor with $1 \mathrm{~cm}$ ID. The reaction was carried out by a mass flow controller at $700{ }^{\circ} \mathrm{C}$ with a flow of $\mathrm{CH}_{4} / \mathrm{N}_{2} 92.5 \% / 7.5 \%(15 \mathrm{~mL} / \mathrm{min})$. The production was analyzed using an online gas chromatograph equipped with a $6 \mathrm{~m} \times 3 \mathrm{~mm}$ HayeSep D 80/100 column (Shimadzu Corporation, Kyoto, Japan) to split $\mathrm{H}_{2}, \mathrm{~N}_{2}, \mathrm{CO}, \mathrm{CO}_{2}, \mathrm{CH}_{4}, \mathrm{C}_{2} \mathrm{H}_{4}$, and $\mathrm{C}_{2} \mathrm{H}_{6}$, and a CBP1-M50-025 quartz capillary column (Shimadzu Corporation, Kyoto, Japan) to separate benzene, toluene, and naphthalene. Helium was used as the carrier gas and the $\mathrm{N}_{2}$ internal standard method of analysis was used to calculate methane conversion and hydrocarbon product selectivity on the basis of carbon mass balance [35].

\section{Result and Discussion}

\subsection{MDA Tests}

It has been reported that non-modified HZSM-5 and Mo/NaZSM-5 catalysts exhibit poor MDA activity due to a lack of active or acidic sites $[5,36,37]$. Although commercial $\mathrm{MoO}_{3}$-modified HMCM-49 showed good MDA activity, stability was poor [20,38]. Figure 1 depicts the tendency of methane to convert and yield to aromatics, benzene, and naphthalene as a function of time in the stream for MDA over the Mo(N)-HMCM-49 catalysts. MDA can generally be divided into two stages. Initially, the Mo-oxo species was carburized to $\mathrm{MoC}_{\mathrm{x}}$ after introducing $\mathrm{CH}_{4}$, and methane conversion and aromatics yield reached quasi-steady values [13,39]. During the second stage, methane conversion and yield reduced gradually, which is ascribed to deactivation by remarkable coke deposition as well as metal carbide species sintering and detaching from MCM-49. Methane conversion over 2Mo(N)-HMCM-49, 
4Mo(N)-HMCM-49, 6Mo(N)-HMCM-49, and 8Mo(N)-HMCM-49 reached a maximum of 8.5\%, 9.7\%, $13.2 \%$, and $12.5 \%$, respectively, and the corresponding aromatics product was 5.8\%, 6.5\%, 9.1\%, and $8.3 \%$. Methane conversion over the catalysts gradually decreased with increasing reaction time. At $580 \mathrm{~min}$, methane conversion over $6 \mathrm{Mo}(\mathrm{N})-\mathrm{HMCM}-49$ was $11.0 \%$, which was higher than over 2Mo(N)-HMCM-49 (3.8\%), 4Mo(N)-HMCM-49 (7.6\%), and 8Mo(N)-HMCM-49 (10.5\%). MCM-49 possesses a set of $12 \mathrm{MR}$ cages connected through $10 \mathrm{MR}$ windows and a set of $10 \mathrm{MR}$ channels. The two pore systems were responsible for the generation of benzene and aromatics [22]. Heavy hydrocarbons and coke deposits were mainly generated over Mo carbides located on the external surface of the zeolite, and thus the methane conversion and aromatics yield have a downward trend due to carbon deposition in the reaction process [40]. Relevant studies have confirmed that Brønsted acid centers can combine well with Mo species, but excessive Brønsted acid centers are conducive to the generation of aromatic carbon deposition, preventing the pore channels of the molecular sieve from deactivating the catalyst [41]. As a result, when the loading of $\mathrm{MoO}_{3}(\mathrm{~N})$ is $6 \%$, the catalyst exhibits optimal performance. We found that $\mathrm{MoO}_{3}(\mathrm{~N})$ can effectively transfer to the pore channels of MCM-49 and interact with Brønsted acid centers to reasonably adjust the distribution of acidic sites, generating more effective active sites to achieve preeminent catalytic performance.
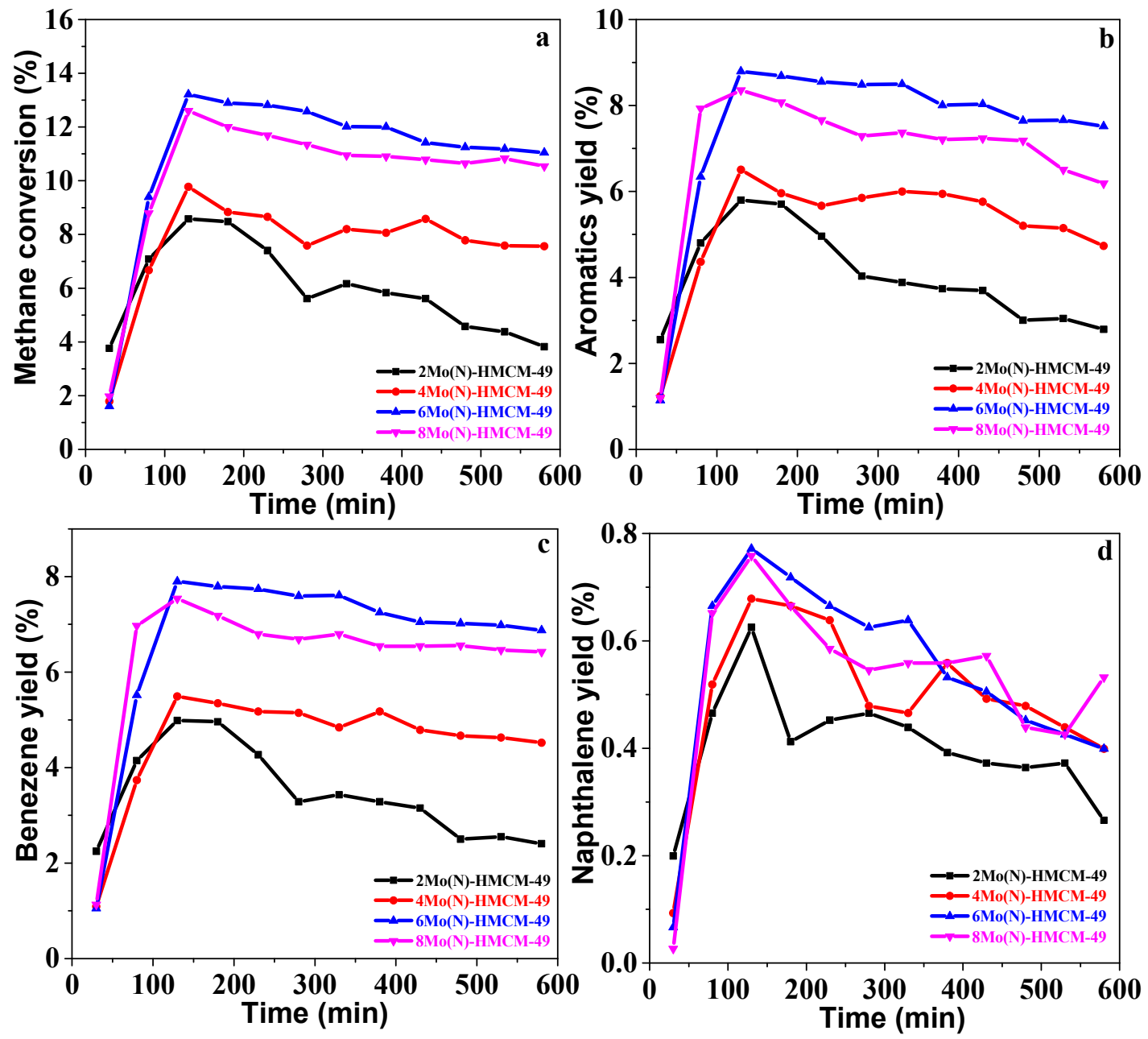

Figure 1. (a) Methane conversion, (b) Aromatics yield, (c) Benzene yield, and (d) Naphthalene yield

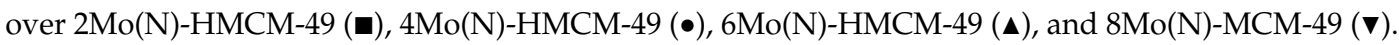
Reaction conditions: $\mathrm{T}$ (temperature) $=700{ }^{\circ} \mathrm{C}, \mathrm{P}$ (pressure) $=1 \mathrm{~atm}, \mathrm{GHSV}$ (gas firing hourly space velocity) $=1500 \mathrm{~h}^{-1}$. 
The methane conversion, selectivity, and aromatics yield over 6Mo(C)-HMCM-49 and 6Mo(N)-HMCM49 in MDA within 580 min are shown in Figure ?? and Table 1. 6Mo(C)-HMCM-49 was deactivated after reacting for $130 \mathrm{~min}$, in agreement with a prior report [34]. Methane conversion over 6Mo(N)-HMCM-49 reached a maximal value of $13.2 \%$, higher than that over $6 \mathrm{Mo}(\mathrm{C})-\mathrm{HMCM}-49(12.1 \%)$. When the reaction reached $580 \mathrm{~min}$, the methane conversion over $6 \mathrm{Mo}(\mathrm{N})-\mathrm{HMCM}-49$ was $11.0 \%$, much higher than over $6 \mathrm{Mo}(\mathrm{C})-\mathrm{HMCM}-49$ (9.6\%). We calculated that 6Mo(N)-HMCM-49 can maintain a higher retention of maximal activity than $6 \mathrm{Mo}(\mathrm{C})-\mathrm{HMCM}-49$ at $580 \mathrm{~min}(83.3 \%$ vs. $79.3 \%)$, indicating better stability with the former. Moreover, the selectivity of benzene over 6Mo(N)-HMCM-49 is higher than over 6Mo(C)-HMCM-49. At $130 \mathrm{~min}$, a $9.1 \%$ aromatics yield is achieved over $6 \mathrm{Mo}(\mathrm{N})-\mathrm{HMCM}-49$, which is higher than over $6 \mathrm{Mo}(\mathrm{C})-\mathrm{HMCM}-49$ (7.6\%). The increased stability may be due to the effective distribution of $\alpha$-MoC $\mathrm{x}_{\mathrm{x}}$ active centers. The status of the catalyst precursor may play a key role in the activity [39]. The metal precursor loading has a variety of configurations on the zeolite, which leads to complicated and broadened signals for most spectroscopic techniques. As discussed below, the pyridine FTIR and NH3-TPD results showed that the acidity of HMCM-49 is altered by nano- $\mathrm{MoO}_{3}$ modification. Furthermore, thermogravimetric analysis showed that nano- $\mathrm{MoO}_{3}$ sublimes more easily than commercial $\mathrm{MoO}_{3}$. As depicted in Figure 3, the weight loss of nano- $\mathrm{MoO}_{3}$ between 700 and $900{ }^{\circ} \mathrm{C}$ was $22.8 \%$, which is higher than that of commercial $\mathrm{MoO}_{3}(19.3 \%)$, demonstrating easier sublimation of the former. As a consequence, nano- $\mathrm{MoO}_{3}$ has better dispersion in the pore channels of MCM-49 and interacts well with Brønsted acid centers to generate more active $\mathrm{MoC}_{\mathrm{x}}$-type centers for MDA, showing higher activity and stability.
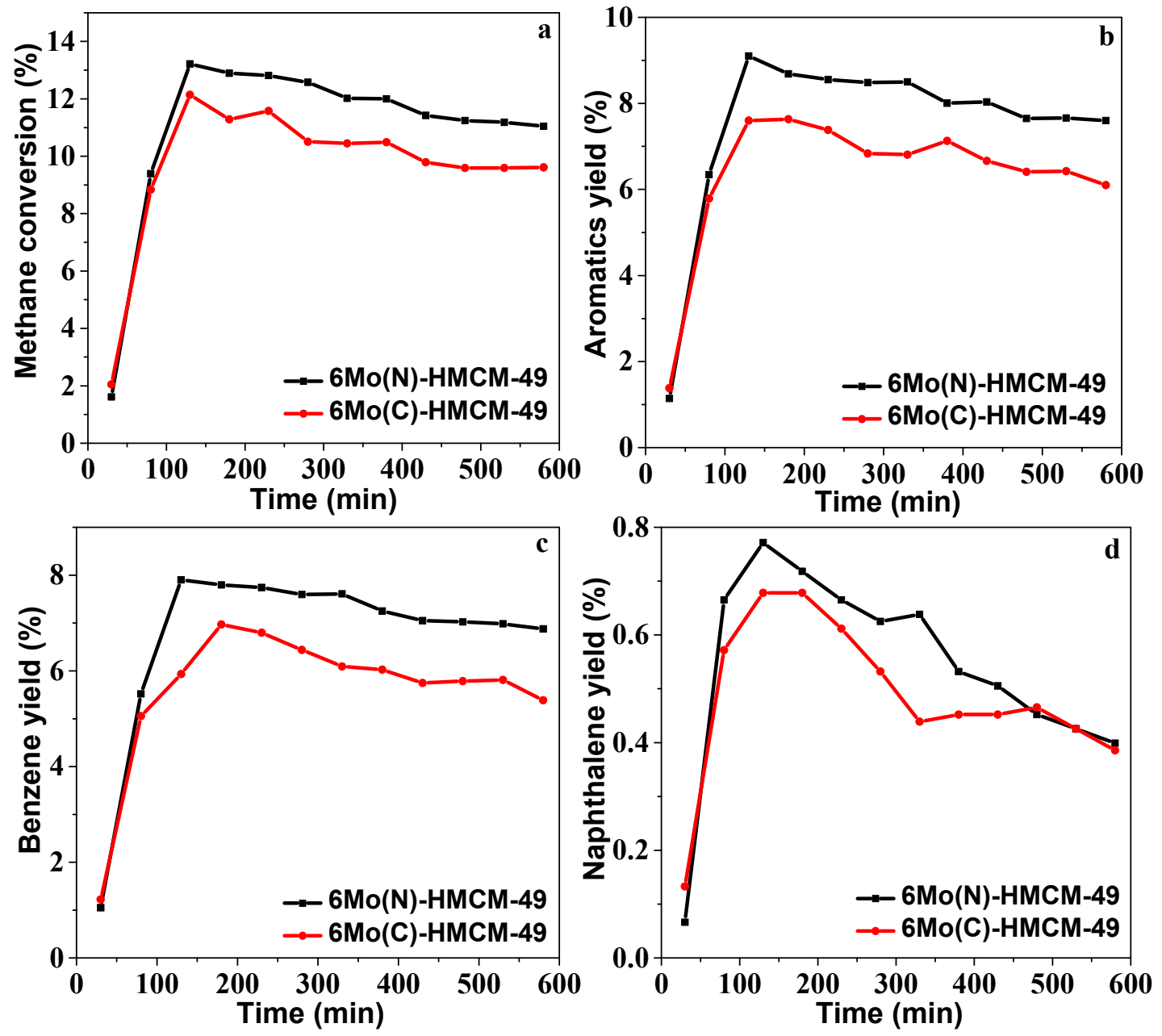

Figure 2. (a) Methane conversion, (b) Aromatics yield, (c) Benzene yield, and (d) Naphthalene yield over $6 \mathrm{Mo}(\mathrm{C})-\mathrm{MCM}-49$ and $6 \mathrm{Mo}(\mathrm{N})-\mathrm{MCM}-49$. Reaction conditions: $\mathrm{T}=700^{\circ} \mathrm{C}, \mathrm{P}=1 \mathrm{~atm}, \mathrm{GHSV}=1500 \mathrm{~h}^{-1}$. 
Table 1. Catalytic results of methane non-oxidative aromatization over various catalysts.

\begin{tabular}{|c|c|c|c|c|c|c|c|}
\hline \multirow{2}{*}{ Catalyst } & \multirow{2}{*}{ Time (min) } & \multirow{2}{*}{$\begin{array}{c}\text { Conversion } \\
(\%)\end{array}$} & \multicolumn{4}{|c|}{ Selectivity (\%) } & \multirow{2}{*}{ Aromatics Yield } \\
\hline & & & Benzene & Toluene & Naphthalene & Coke & \\
\hline \multirow{2}{*}{ 6Mo(C)-MCM-49 } & 130 & 12.1 & 54.5 & 4.0 & 4.1 & 37.4 & 7.6 \\
\hline & 580 & 9.6 & 55.2 & 4.1 & 4.1 & 36.6 & 6.1 \\
\hline \multirow{2}{*}{$6 \mathrm{Mo}(\mathrm{N})-\mathrm{MCM}-49$} & 130 & 13.2 & 59.8 & 4.5 & 5.3 & 30.4 & 9.1 \\
\hline & 580 & 11.0 & 61.8 & 4.5 & 4.0 & 29.7 & 7.7 \\
\hline
\end{tabular}

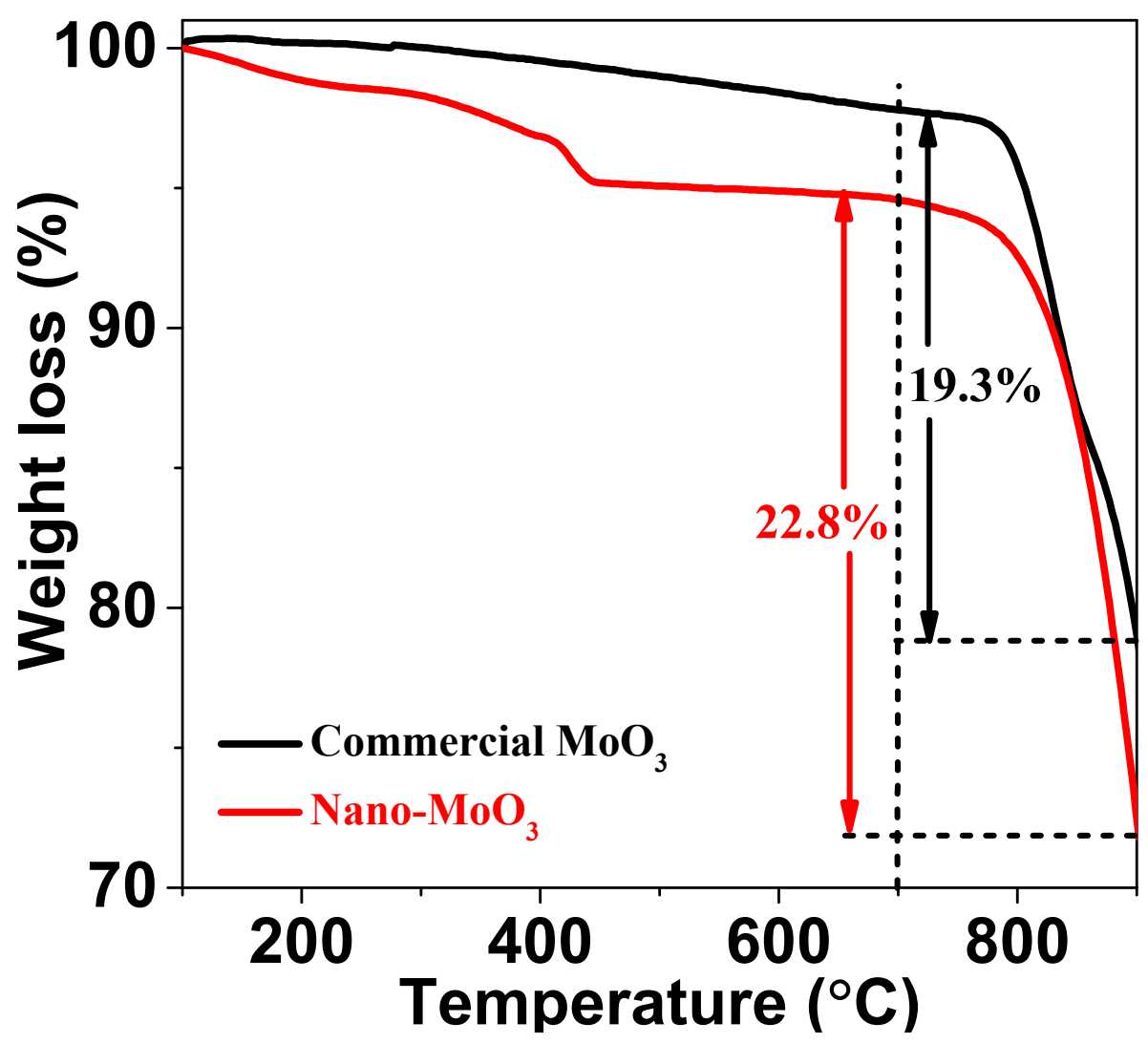

Figure 3. Thermogravimetric analysis of commercial $\mathrm{MoO}_{3}$ and ano- $\mathrm{MoO}_{3}$.

\subsection{XRD Characterization}

To reveal the crystallinity structure of nano- $\mathrm{MoO}_{3}$ and $\mathrm{Mo}(\mathrm{N})-\mathrm{HMCM}-49$, XRD characterization was performed. As shown in Figure $4 \mathrm{~A}$, the sharp diffraction peaks of nano- $\mathrm{MoO}_{3}$ at $2 \theta=12.9^{\circ}$ and $27.4^{\circ}$ confirm a highly crystalline $\alpha-\mathrm{MoO}_{3}$ orthorhombic phase. The diffraction peak intensity of (021) planes was quite high, indicating a crystal orientation along (001) [42]. The crystallite size of $\mathrm{MoO}_{3}(\mathrm{~N})$ was estimated to be about $22 \mathrm{~nm}$. The XRD patterns of HMCM-49 and Mo species-doped HMCM-49 are shown in Figure 4B. The peaks at $2 \theta$ of $7.1^{\circ}, 8.0^{\circ}, 10^{\circ}, 14.2^{\circ}, 22^{\circ}, 26^{\circ}$, and $37.9^{\circ}$ for MCM-49 were due to 100, 101, 102, 200, 302, 310, and 330 crystal planes, respectively [16]. All catalysts exhibited characteristic peaks of MCM-49. Nevertheless, the peak intensity of $\mathrm{MoO}_{3}(\mathrm{~N})$-modified MCM-49 decreased compared to pristine HMCM-49, suggesting that the diffusion of $\mathrm{MoO}_{3}$ in the pores causes the loss of crystallinity. No obvious peaks due to $\mathrm{MoO}_{3}$ were observed even at high Mo loadings, implying that $\mathrm{MoO}_{3}$ nanoparticles were well dispersed on the surface and in the channels of HMCM-49. Moreover, as compared to the $6 \mathrm{Mo}(\mathrm{C})-\mathrm{HMCM}-49$ catalyst (Figure $4 \mathrm{~h}$ ), the $6 \mathrm{Mo}(\mathrm{N})-\mathrm{HMCM}-49$ sample showed lower crystallinity (Figure 4f), especially for the 310- and 330-crystal planes, which confirms that more Mo-species migrated to HMCM-49 channels. 

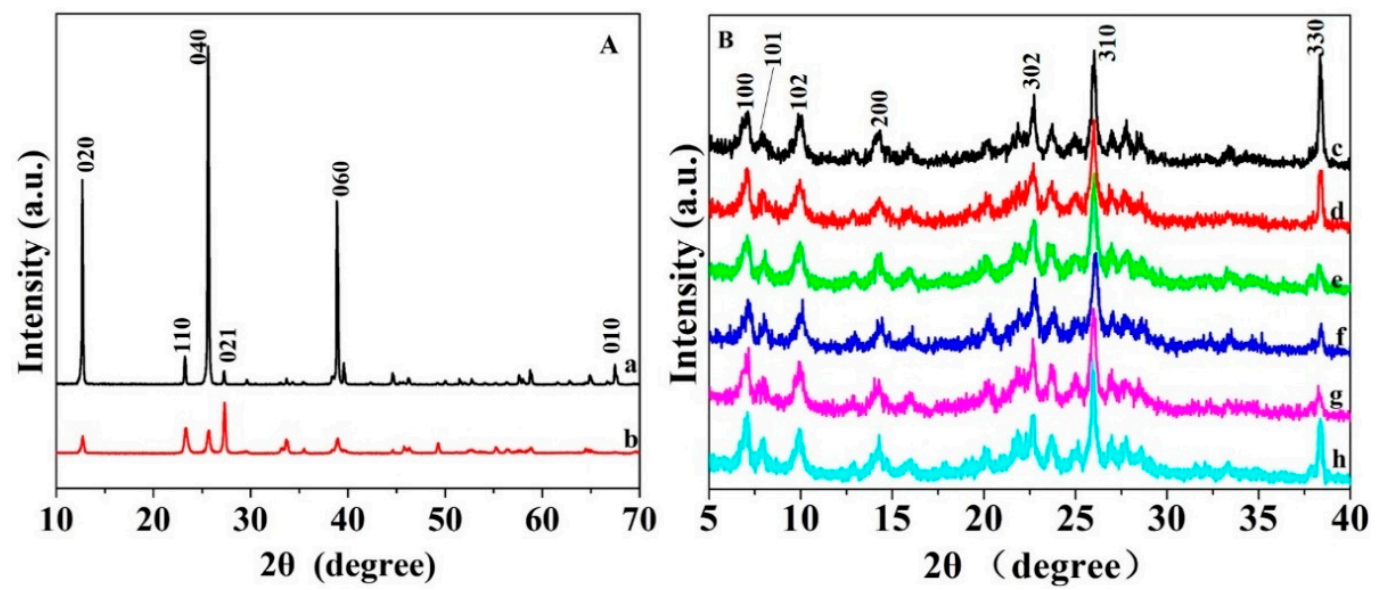

Figure 4. XRD patterns in (A): (a) $\mathrm{MoO}_{3}(\mathrm{C})$ and (b) $\mathrm{MoO}_{3}(\mathrm{~N})$ and (B): (c) $\mathrm{HMCM}-49$, (d) $2 \mathrm{Mo}(\mathrm{N})-\mathrm{HMCM}-49$, (e) $4 \mathrm{Mo}(\mathrm{N})-\mathrm{HMCM}-49$, (f) 6Mo(N)-HMCM-49, (g) 8Mo(N)-HMCM-49, and (h) 6Mo(C)-HMCM-49.

\subsection{SEM Characterization}

The morphology of commercial $\mathrm{MoO}_{3}, \mathrm{MoO}_{3}(\mathrm{~N}), \mathrm{HMCM}-49$, and $6 \mathrm{Mo}(\mathrm{N})-\mathrm{HMCM}-49$ was analyzed by SEM. As shown in Figure 5, the particle size of commercial $\mathrm{MoO}_{3}$ is larger than $1 \mu \mathrm{m}$, whereas the particle size of $\mathrm{MoO}_{3}(\mathrm{~N})$ is less than $50 \mathrm{~nm}$. In addition, we clearly observed that HMCM-49 has a platelet-like shape, in accordance with the literature [43]. MCM-49 has a length of less than $500 \mathrm{~nm}$ and a thickness of less than $50 \mathrm{~nm}$. The morphology of MCM-49 did not significantly change after nano- $\mathrm{MoO}_{3}$ modification. Some small crystallites were found on the surface of $6 \mathrm{Mo}(\mathrm{N})-\mathrm{HMCM}-49$, which was attributed to the cracking of large MCM- 49 crystallites by grinding. The surface of MCM- 49 modified with commercial $\mathrm{MoO}_{3}$ presented larger particles, which may be attributed to more commercial $\mathrm{MoO}_{3}$ located on the external surface of the zeolite. The above results further evidence that nano- $\mathrm{MoO}_{3}$ more easily sublimates and diffuses into the zeolite channels.
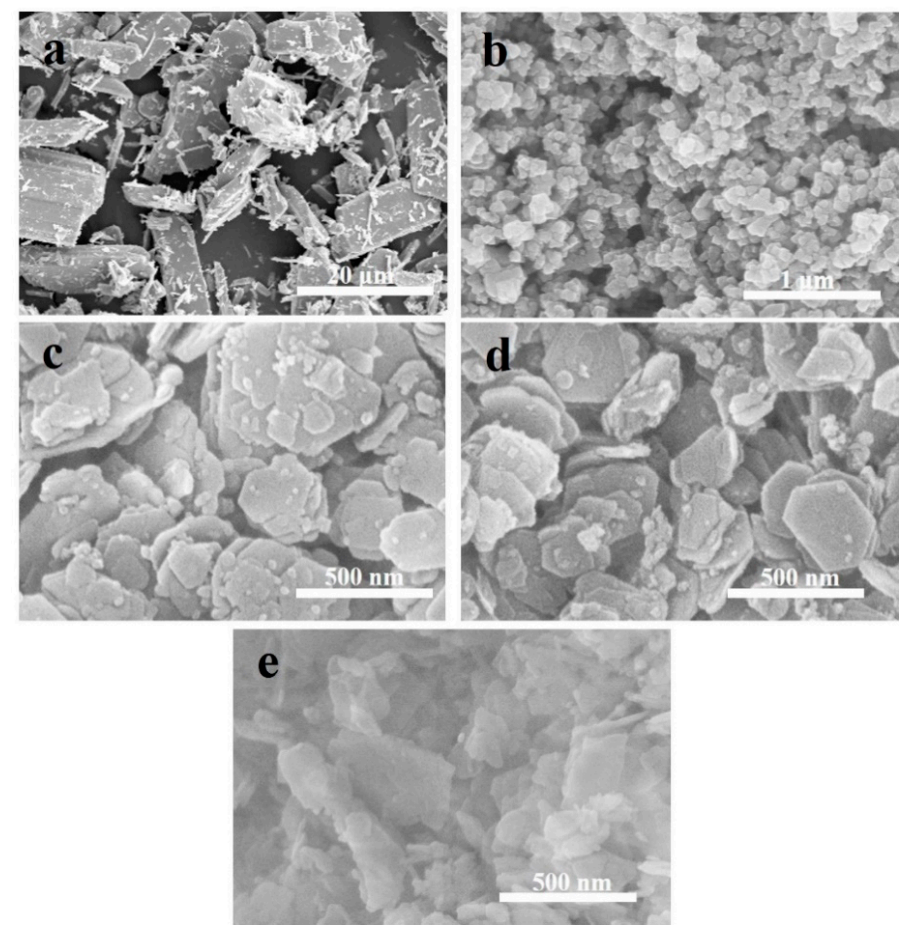

Figure 5. SEM images of (a) commercial $\mathrm{MoO}_{3},\left(\right.$ b) $\mathrm{MoO}_{3}(\mathrm{~N})$, (c) HMCM-49, (d) $6 \mathrm{Mo}(\mathrm{N})-\mathrm{HMCM}-49$, and $(\mathbf{e}) 6 \mathrm{Mo}(\mathrm{C})-\mathrm{HMCM}-49$. 


\subsection{TEM Characterization}

The morphology of $6 \mathrm{Mo}(\mathrm{N})-\mathrm{HMCM}-49$ was further characterized by TEM. As illustrated in Figure 6, a thin plate-like shape was typically observed for the MCM-49-based materials, in agreement with the SEM results. To identify the dispersion of Mo species in HMCM-49, EDS analysis was performed. As exhibited in Figure 7, 6Mo(N)-HMCM-49 contained $\mathrm{Si}$, Al, O, and Mo elements, which were uniformly dispersed. Comparatively, the Mo species exhibited worse distribution in 6Mo(C)-HMCM-49 (Figure 8).

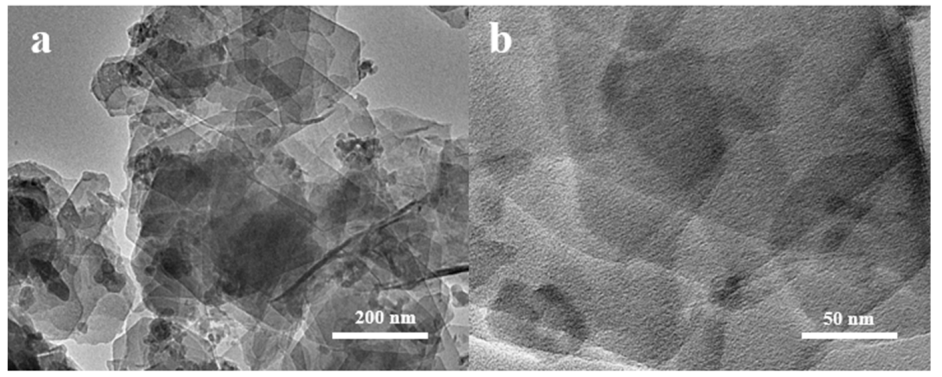

Figure 6. (a,b) TEM images of 6Mo(N)-HMCM-49 with different magnifications.
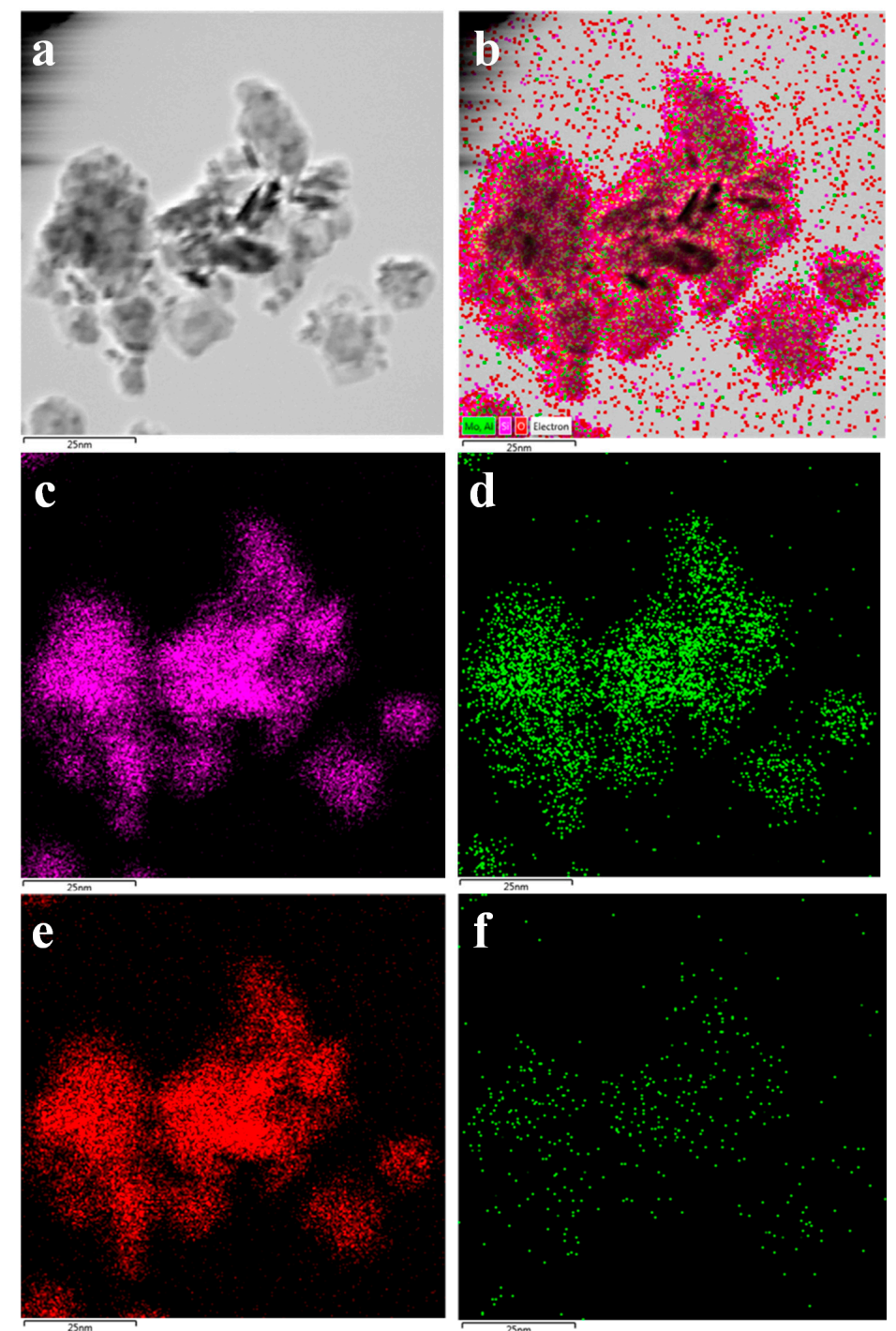

Figure 7. TEM image of $6 \mathrm{Mo}(\mathrm{N})-\mathrm{HMCM}-49$ used in the EDS mapping test (a), and the corresponding EDS mapping of various elements (b), $\mathrm{Si}(\mathbf{c}), \mathrm{Al}(\mathbf{d}), \mathrm{O}(\mathbf{e})$, and $\mathrm{Mo}(\mathbf{f})$. 

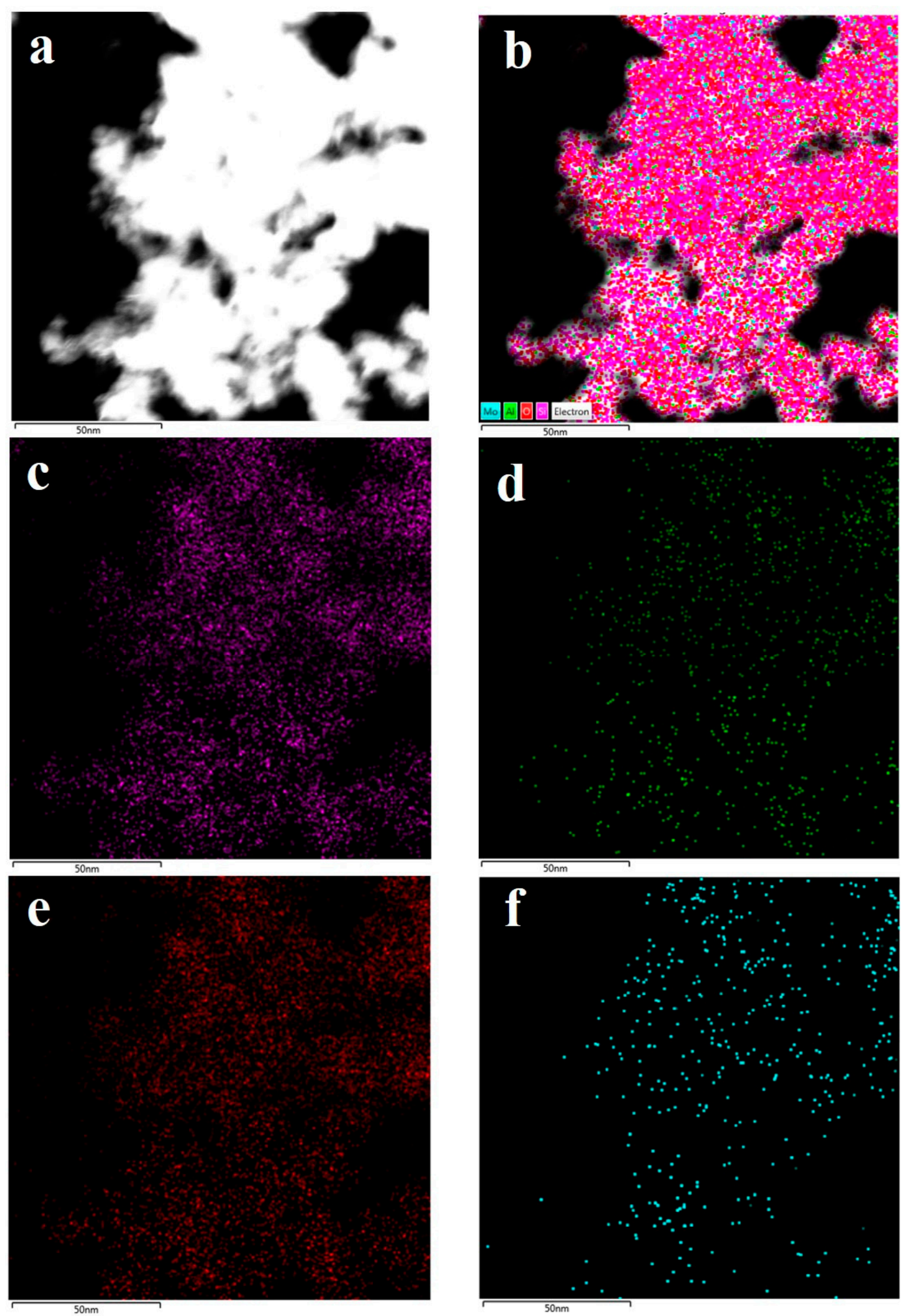

Figure 8. TEM image of $6 \mathrm{Mo}(\mathrm{C})-\mathrm{HMCM}-49$ used in the EDS mapping test (a) and the corresponding EDS mapping of various elements (b), $\mathrm{Si}(\mathbf{c}), \mathrm{Al}(\mathbf{d}), \mathrm{O}(\mathbf{e})$, and $\mathrm{Mo}(\mathbf{f})$. 


\section{5. $\mathrm{N}_{2}$ Adsorption-Desorption Characterization}

The textural properties of HMCM-49 and 6Mo(N)-MCM-49 were revealed by $\mathrm{N}_{2}$ adsorption-desorption isotherms and pore size distributions extracted from the adsorption branch of isotherms (Figure 9 and Table 2). The isotherm of MCM-49 is typical isotherm I, indicating a microporous zeolite. A steep line at relatively low pressure is associated with capillary condensation in micropores of the HMCM-49 zeolite. A narrow hysteresis loop can be seen for $\mathrm{MCM}-49$ at $\mathrm{P} / \mathrm{P}^{0}=0.6-1.0$, indicating the presence of slit-mesopore platelet particles most likely derived from the aggregation of stratified particles. The micropore area and volume of Mo/HMCM-49 gradually decreased with a continually increasing content of nano- $\mathrm{MoO}_{3}$ loadings, indicating that the content of $\mathrm{MoO}_{3}(\mathrm{~N})$ has a specific effect on the structural parameters of HMCM-49. The specific surface area decreased from 482 to $379 \mathrm{~cm}^{2} / \mathrm{g}$ and micropore volume decreased from 0.16 to $0.12 \mathrm{~cm}^{3} / \mathrm{g}$ after loading $6 \mathrm{wt} \% \mathrm{MoO}_{3}(\mathrm{~N})$. These results imply that Mo species migrate into the zeolitic channels, where the Mo-oxo species can anchor on the external/internal surface of the zeolite and lead to a decrease in specific surface area and pore volume [44]. In addition, the specific surface area of $6 \mathrm{Mo}(\mathrm{N})-\mathrm{MCM}-49$ was smaller than that of $6 \mathrm{Mo}(\mathrm{C})-\mathrm{MCM}-49$, implying that nano- $\mathrm{MoO}_{3}$ shows better dispersion in the micropore channel of the HMCM-49 zeolite due to easier sublimation of nano- $\mathrm{MoO}_{3}$ than commercial $\mathrm{MoO}_{3}$.
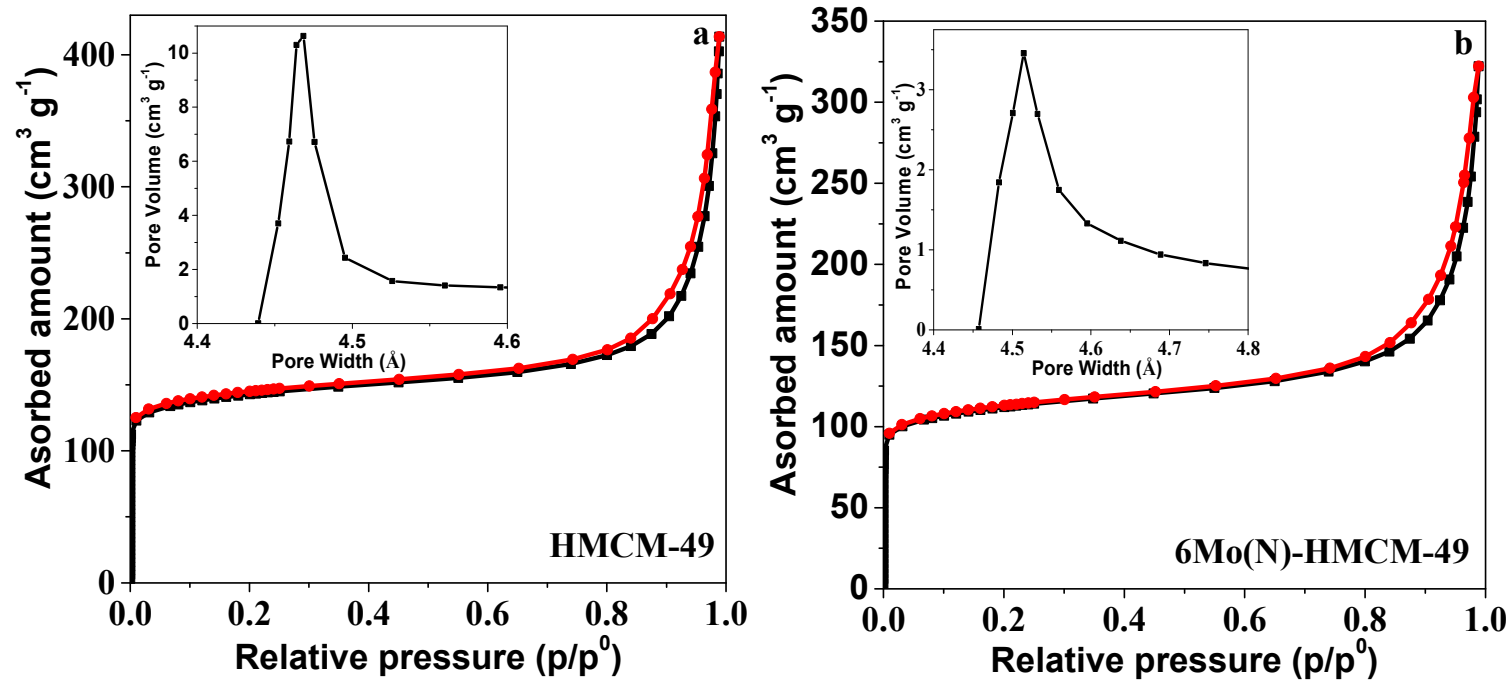

Figure 9. Nitrogen adsorption-desorption isotherms and pore size distributions of (a) HMCM-49 and (b) $6 \mathrm{Mo}(\mathrm{N})-\mathrm{MCM}-49$.

Table 2. Textural properties of HMCM-49, 6Mo(C)-HMCM-49, and HMCM-49 modified with different contents of nano- $\mathrm{MoO}_{3}$.

\begin{tabular}{|c|c|c|c|}
\hline Sample & $\begin{array}{c}\text { Surface Area } \\
\left(\mathrm{m}^{2} / \mathrm{g}\right)\end{array}$ & $\begin{array}{l}\text { Micropore Area } \\
\left(\mathrm{m}^{2} / \mathrm{g}\right)\end{array}$ & $\begin{array}{l}\text { Micropore Volume } \\
\left(\mathrm{cm}^{3} / \mathrm{g}\right)\end{array}$ \\
\hline HМCM-49 & 482 & 353 & 0.16 \\
\hline 6Mo(C)-HMCM-49 & 404 & 270 & 0.12 \\
\hline $2 \mathrm{Mo}(\mathrm{N})-\mathrm{HMCM}-49$ & 469 & 337 & 0.15 \\
\hline $4 \mathrm{Mo}(\mathrm{N})-\mathrm{HMCM}-49$ & 404 & 280 & 0.13 \\
\hline $6 \mathrm{Mo}(\mathrm{N})-\mathrm{HMCM}-49$ & 379 & 263 & 0.12 \\
\hline $8 \mathrm{Mo}(\mathrm{N})-\mathrm{HMCM}-49$ & 367 & 275 & 0.12 \\
\hline
\end{tabular}

\subsection{Acidity Characterization}

The acidity of Mo/HMCM-49 was analyzed by $\mathrm{NH}_{3}$-TPD. As shown in Figure 10, different desorption temperatures of $\mathrm{NH}_{3}$-TPD can reflect acid strength. The low temperature peak in the range of $200-300{ }^{\circ} \mathrm{C}$ is ascribed to the decomposition of physically adsorbed $\mathrm{NH}_{3}$ on the catalyst, while the high temperature peak between 400 and $500{ }^{\circ} \mathrm{C}$ is attributed to the decomposition of $\mathrm{NH}_{3}$ adsorbed on 
Brønsted acid sites [45]. The $\mathrm{NH}_{3}$-TPD profiles exhibited a new peak at ca. $360^{\circ} \mathrm{C}$ after fitting curves, as shown in Figure 11, which is related to the desorption of the $\mathrm{NH}_{3}$ adsorbed on exchangeable protonic sites. After loading $\mathrm{MoO}_{3}$, the peak associated with Brønsted acid sites became weak, indicating that a portion of strong acid sites interacts with the Mo species [43]. In addition, the acid strength of the catalyst gradually decreased with the increase in nano- $\mathrm{MoO}_{3}$, further confirming that $\mathrm{MoO}_{3}(\mathrm{~N})$ reacts with the acidic sites of HMCM-49 [46]. The relative amounts of acid sites in HMCM-49 and Mo-HMCM-49 were calculated by Gaussian fitting. As shown in Table 3, the Brønsted acid strength of $\mathrm{MoO}_{3}(\mathrm{~N})-\mathrm{HMCM}-49$ decreased more significantly than $6 \mathrm{Mo}(\mathrm{C})-\mathrm{HMCM}-49$ when the same amount of $\mathrm{MoO}_{3}$ was loaded, suggesting that more $\mathrm{MoO}_{3}(\mathrm{~N})$ species migrate into the channels of the zeolite and bind with Brønsted acid sites.

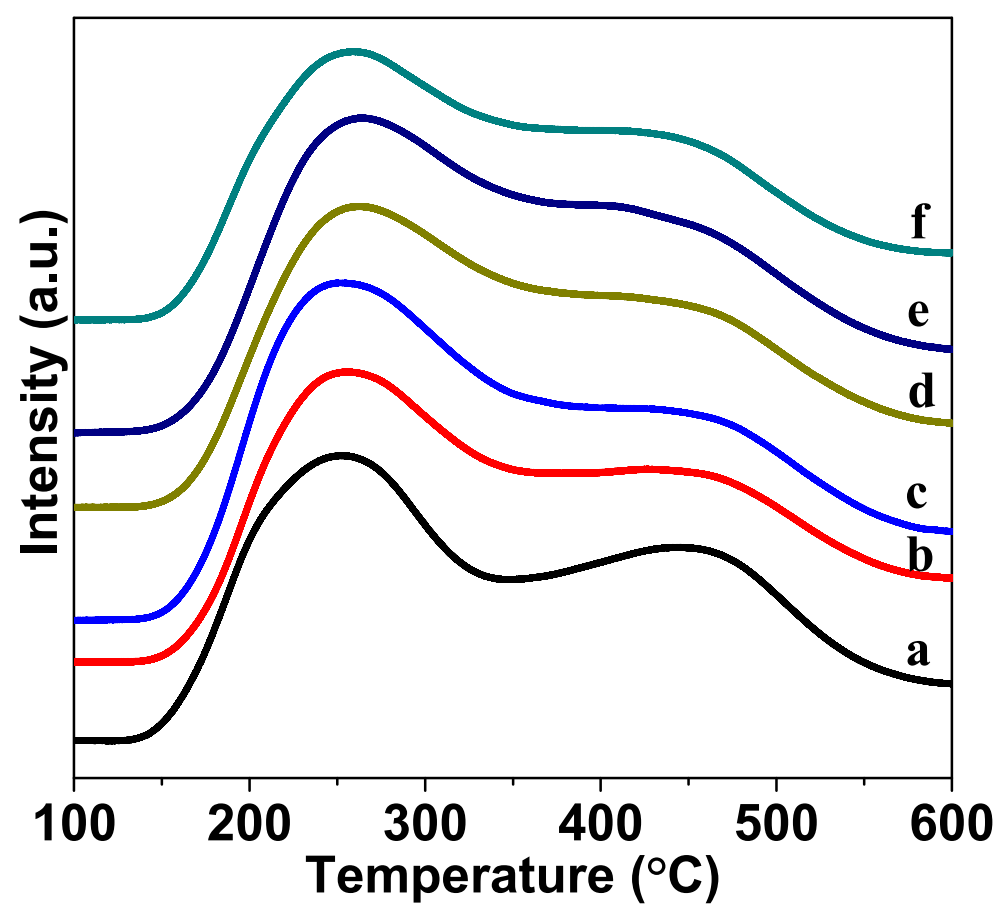

Figure 10. $\mathrm{NH}_{3}$-TPD profiles of (a) HMCM-49, (b) 2Mo(N)-HMCM-49, (c) 4Mo(N)-HMCM-49, (d) $6 \mathrm{Mo}(\mathrm{N})-\mathrm{HMCM}-49$, (e) $8 \mathrm{Mo}(\mathrm{N})-\mathrm{HMCM}-49$, and (f) $6 \mathrm{Mo}(\mathrm{C})-\mathrm{HMCM}-49$.
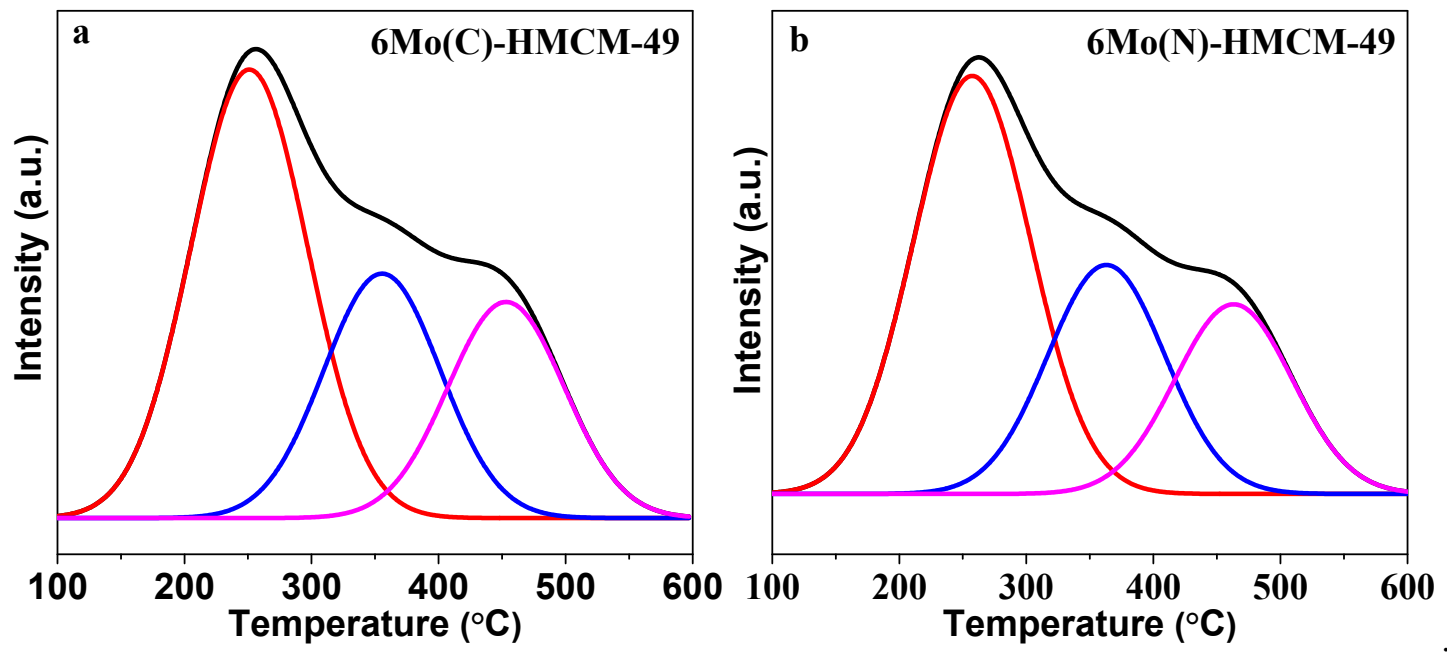

Figure 11. $\mathrm{NH}_{3}-\mathrm{TPD}$ profiles of the $6 \mathrm{Mo}(\mathrm{C})-\mathrm{HMCM}-49$ and $6 \mathrm{Mo}(\mathrm{N})-\mathrm{HMCM}-49$ catalysts after fitting curves.(a) $6 \mathrm{Mo}(\mathrm{C})-\mathrm{HMCM}-49,(\mathbf{b}) 6 \mathrm{Mo}(\mathrm{N})-\mathrm{HMCM}-49$ 
Table 3. Peak temperature of $\mathrm{NH}_{3}$-TPD spectra and the relative amounts of acid sites in HMCM-49 and Mo-HMCM-49.

\begin{tabular}{ccccccc}
\hline \multirow{2}{*}{ Samples } & Peak (L) & \multicolumn{3}{c}{ Peak (M) } & \multicolumn{3}{c}{ Peak (H) } \\
\cline { 2 - 7 } & $\begin{array}{c}\text { Peak Temp } \\
\left({ }^{\circ} \text { C) }\right.\end{array}$ & $\begin{array}{c}\text { Area } \\
\text { Unit }\end{array}$ & $\begin{array}{c}\text { Peak Temp } \\
\left({ }^{\circ} \text { C) }\right.\end{array}$ & $\begin{array}{c}\text { Area } \\
\text { Unit }\end{array}$ & $\begin{array}{c}\text { Peak Temp } \\
\left({ }^{\circ} \text { C) }\right.\end{array}$ & $\begin{array}{c}\text { Area } \\
\text { Unit }\end{array}$ \\
\hline HMCM-49 & 228 & 445 & & & 416 & 627 \\
6 Mo(N)-HMCM-49 & 223 & 315 & 277 & 175 & 414 & 325 \\
6 Mo(C)-HMCM-49 & 231 & 338 & 287 & 198 & 424 & 412 \\
\hline
\end{tabular}

The acidity of Mo/HMCM-49 was further characterized by pyridine FTIR measurements. As exhibited in Figure 12, the adsorption of pyridine on Brønsted acid sites was about $1540 \mathrm{~cm}^{-1}$, whereas the adsorption of pyridine on Lewis acid sites corresponded to a peak of about $1450 \mathrm{~cm}^{-1}$ [47]. The peak of about $1489 \mathrm{~cm}^{-1}$ is related to pyridine interacting with medium-strength acid sites. The acid strength of Brønsted acid sites and Lewis acid sites clearly decreased with the increasing content of nano- $\mathrm{MoO}_{3}$ loadings, which is consistent with the TPD results above. It has been reported that the formation of highly dispersed Mo species associated with the internal Brønsted acid sites is crucial for methane non-aromatization $[18,48]$. The smaller the size of the $\mathrm{MoO}_{3}$ particles, the better the dispersion of Mo species in the zeolite channels.

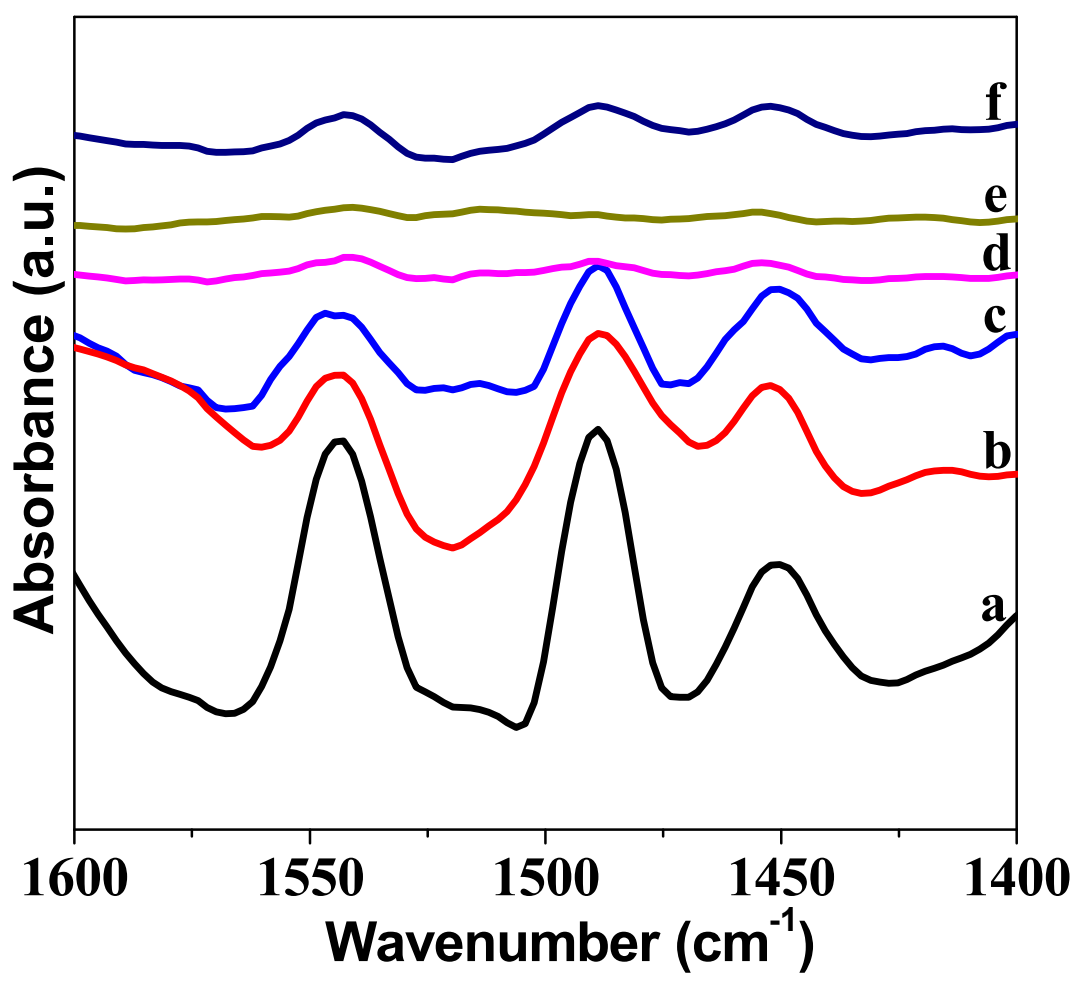

Figure 12. FTIR spectra in the pyridine region after desorption of the base at $100{ }^{\circ} \mathrm{C}$ : (a) HMCM-49, (b) $2 \mathrm{Mo}(\mathrm{N})-\mathrm{HMCM}-49$, (c) $4 \mathrm{Mo}(\mathrm{N})-\mathrm{HMCM}-49$, (d) 6Mo(N)-HMCM-49, (e) 8Mo(N)-HMCM-49, and (f) $6 \mathrm{Mo}(\mathrm{C})-\mathrm{HMCM}-49$.

\subsection{Thermogravimetric Analysis of the Catalysts After Reactions}

As depicted in Figure 13, weight loss below $200^{\circ} \mathrm{C}$ is associated with absorbed water. Weight loss at $350-450^{\circ} \mathrm{C}$ is due to the oxidation of Mo carbide species. The noteworthy weight loss between 400 and $800^{\circ} \mathrm{C}$ is assigned to the burn-off of carbon deposition formed on the zeolite [49]. Benzene forms mainly in the pore channels of the zeolites, while naphthalene forms mainly on the surface and orifices of the zeolites [50]. Carbonaceous deposition in the zeolite channels may prompt the loss of partial 
active centers and block the zeolite channels, thus causing catalyst deactivation. During the reaction induction period, carbon deposition reached a maximal value of selectivity over $6 \mathrm{Mo}(\mathrm{C})-\mathrm{HMCM}-49$ and $6 \mathrm{Mo}(\mathrm{N})-\mathrm{HMCM}-49$ of $37.4 \%$ and $30.4 \%$, respectively. As the reaction continued, the selectivity of carbon deposition decreased. The weightlessness of $6 \mathrm{Mo}(\mathrm{C})-\mathrm{HMCM}-49$ and $6 \mathrm{Mo}(\mathrm{N})-\mathrm{HMCM}-49$ after reacting for 580 min was about $12.6 \%$ and $9.6 \%$, respectively, proving that $6 \mathrm{Mo}(\mathrm{N})-\mathrm{HMCM}-49$ shows better resistance to carbon deposition than $6 \mathrm{Mo}(\mathrm{C})$-HMCM-49. According to pyridine FTIR and $\mathrm{NH}_{3}-\mathrm{TPD}$ results, more active $\mathrm{MoC}_{\mathrm{x}}$-type sites are generated in micropores of nano- $\mathrm{MoO}_{3}$-doped $\mathrm{HMCM}-49$, which favors benzene for improvement of selectivity and results in better catalytic performance.

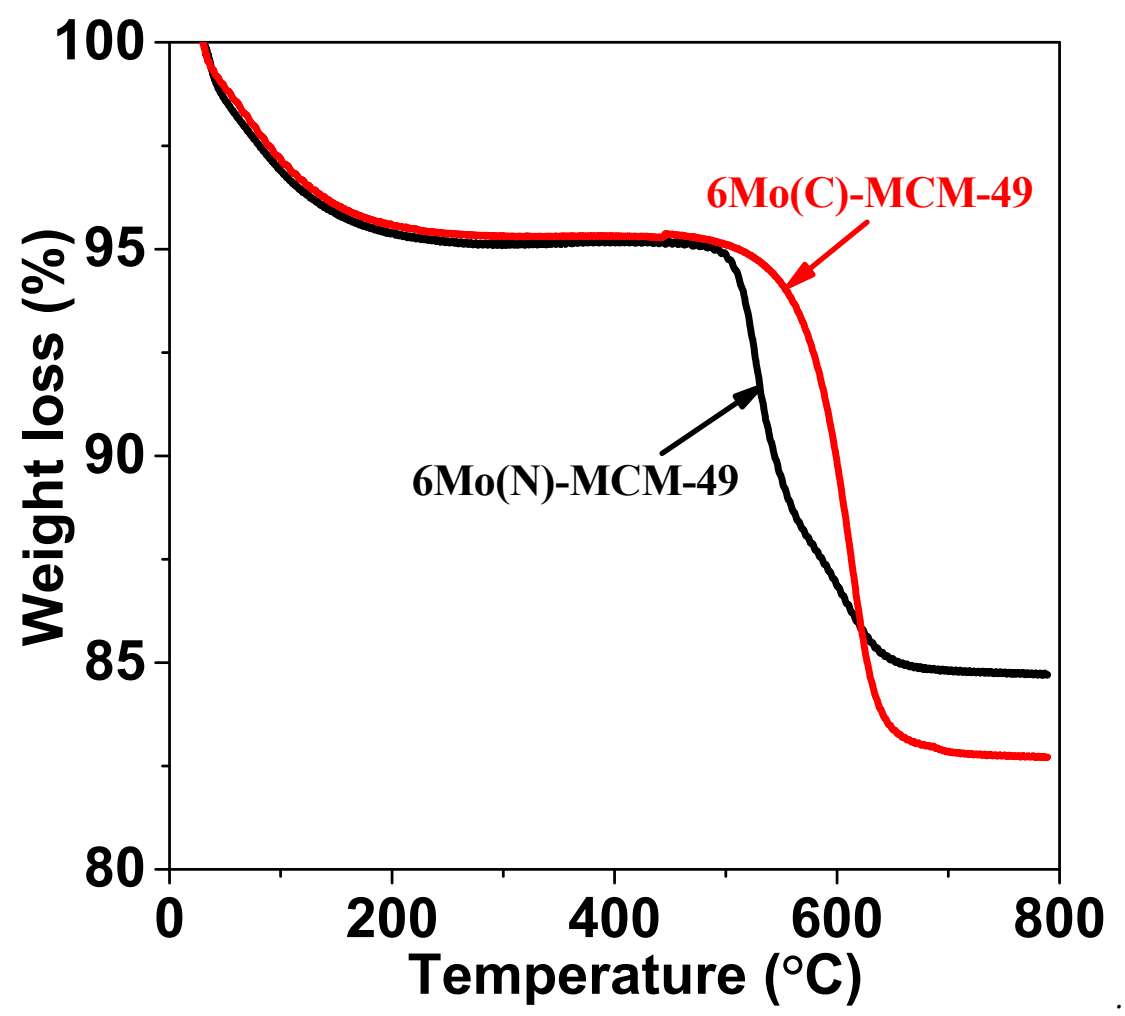

Figure 13. Thermogravimetric analysis of $6 \mathrm{Mo}(\mathrm{C})-\mathrm{HMCM}-49$ and $6 \mathrm{Mo}(\mathrm{N})-\mathrm{HMCM}-49$ after reacting for $580 \mathrm{~min}$. The catalysts after reaction were analyzed by TGA.

\section{Conclusions}

In summary, we found that nano- $\mathrm{MoO}_{3}$-modified $\mathrm{MCM}-49$ showed better MDA performance than commercial $\mathrm{MoO}_{3}$-modified MCM-49, achieving $13.2 \%$ of methane conversion and $9.1 \%$ of aromatics yield. Due to its small size, nano- $\mathrm{MoO}_{3}$ can sublimate more easily and diffuse into the channels to react with MCM- 49 acid sites and form active $\mathrm{MoC}_{\mathrm{x}}$-type sites, which can prevent the blocking of pores and improve stability. This study provided a facile strategy to synthesize high-performance and stable catalysts for MDA.

Author Contributions: Conceptualization, J.G. and Q.K.; writing—original draft preparation, J.H.; writing—review and editing, J.G.; investigation, Y.L., P.L., and Y.W.; data curation, J.L. (Jinghai Liu) and J.L. (Jinglin Liu). All authors have read and agreed to the published version of the manuscript.

Funding: This research was funded by the Doctoral Scientific Research Foundation of Inner Mongolia University for Nationalities (BS379, BS245, BS437, BS397), the Inner Mongolia Natural Science Foundation (2017BS0205, 2019BS02008, 2019BS02007, 2018BS02005), and the Scientific Research Projects of the Inner Mongolian Higher Educational System (NJZZ20110).

Conflicts of Interest: The authors declare no conflict of interest. 


\section{References}

1. Velebná, K.; Horňáček, M.; Jorík, V.; Hudec, P.; Čaplovičová, M.; Čaplovič, L.U. The influence of molybdenum loading on activity of ZSM-5 zeolite in dehydroaromatization of methane. Microporous Mesoporous Mater. 2015, 212, 146-155. [CrossRef]

2. Han, S.J.; Kim, S.K.; Hwang, A.; Kim, S.; Hong, D.-Y.; Kwak, G.; Jun, K.-W.; Kim, Y.T. Non-oxidative dehydroaromatization of methane over Mo/H-ZSM-5 catalysts: A detailed analysis of the reaction-regeneration cycle. Appl. Catal. B-Environ. 2019, 241, 305-318. [CrossRef]

3. Portilla, M.T.; Llopis, F.J.; Martínez, C. Non-oxidative dehydroaromatization of methane: An effective reaction-regeneration cyclic operation for catalyst life extension. Catal. Sci. Technol. 2015, 5, 3806-3821. [CrossRef]

4. Guo, A.; Wu, C.; He, P.; Luan, Y.; Zhao, L.; Shan, W.; Cheng, W.; Song, H. Low-temperature and low-pressure non-oxidative activation of methane for upgrading heavy oil. Catal. Sci. Technol. 2016, 6, 1201-1213. [CrossRef]

5. Wang, L.; Tao, L.; Xie, M.; Xu, G.; Huang, J.; Xu, Y. Dehydrogenation and aromatization of methane under non-oxidizing conditions. Catal. Lett. 1993, 21, 35-41. [CrossRef]

6. He, P.; Jarvis, J.S.; Meng, S.; Li, Q.; Bernard, G.M.; Liu, L.; Mao, X.; Jiang, Z.; Zeng, H.; Michaelis, V.K.; et al. Co-aromatization of methane with propane over Zn/HZSM-5: The methane reaction pathway and the effect of Zn distribution. Appl. Catal. B-Environ. 2019, 250, 99-111. [CrossRef]

7. Denardin, F.; Perez-Lopez, O.W. Tuning the acidity and reducibility of Fe/ZSM-5 catalysts for methane dehydroaromatization. Fuel 2019, 236, 1293-1300. [CrossRef]

8. Vollmer, I.; Mondal, A.; Yarulina, I.; Abou-Hamad, E.; Kapteijn, F.; Gascon, J. Quantifying the impact of dispersion, acidity and porosity of Mo/HZSM-5 on the performance in methane dehydroaromatization. Appl. Catal. A-Gen. 2019, 574, 144-150. [CrossRef]

9. Kosinov, N.; Coumans, F.J.A.G.; Li, G.; Uslamin, E.; Mezari, B.; Wijpkema, A.S.G.; Pidko, E.A.; Hensen, E.J.M. Stable Mo/HZSM-5 methane dehydroaromatization catalysts optimized for high-temperature calcinationregeneration. J. Catal. 2017, 346, 125-133. [CrossRef]

10. Kosinov, N.; Uslamin, E.A.; Meng, L.; Parastaev, A.; Liu, Y.; Hensen, E.J.M. Reversible nature of coke formation on Mo/ZSM-5 methane dehydroaromatization catalysts. Angew. Chem. Int. Ed. 2019, 58, 7068-7072. [CrossRef]

11. Corredor, E.C.; Chitta, P.; Deo, M.D. Techno-economic evaluation of a process for direct conversion of methane to aromatics. Fuel Process. Technol. 2019, 183, 55-61. [CrossRef]

12. Gao, J.; Zheng, Y.; Jehng, J.-M.; Tang, Y.; Wachs, I.E.; Podkolzin, S.G. Identification of molybdenum oxide nanostructures on zeolites for natural gas conversion. Science 2015, 348, 686. [CrossRef] [PubMed]

13. Vollmer, I.; Bart, V.D.L.; Ould-Chikh, S.; Aguilar Tapia, A.; Yarulina, I.; Abou-Hamad, E.; Sneider, Y.G.; Olivos Suarez, A.; Hazemann, J.L.; Kapteijn, F.J.C.E. On the dynamic nature of Mo sites for methane dehydroaromatization. Chem. Sci. 2018, 9, 4801-4807. [CrossRef] [PubMed]

14. Liu, B.S.; Jiang, L.; Sun, H.; Au, C.T. XPS, XAES, and TG/DTA characterization of deposited carbon in methane dehydroaromatization over Ga-Mo/ZSM-5 catalyst. Appl. Surf. Sci. 2007, 253, 5092-5100. [CrossRef]

15. Ma, D.; Shu, Y.; Cheng, M.; Xu, Y.; Bao, X. On the induction period of methane aromatization over Mo-based catalysts. J. Catal. 2000, 194, 105-114. [CrossRef]

16. Zheng, H.; Ma, D.; Bao, X.; Hu, J.Z.; Kwak, J.H.; Wang, Y.; Peden, C.H.F. Direct observation of the active center for methane dehydroaromatization using an ultrahigh ield ${ }^{95} \mathrm{Mo}$ NMR spectroscopy. J. Am. Chem. Soc. 2008, 130, 3722-3723. [CrossRef]

17. Li, W.; Meitzner, G.D.; Borry, R.W.; Iglesia, E. Raman and X-Ray Absorption Studies of Mo Species in Mo/H-ZSM5 Catalysts for Non-oxidative $\mathrm{CH}_{4}$ Reactions. J. Catal. 2000, 191, 373-383. [CrossRef]

18. Vollmer, I.; Yarulina, I.; Kapteijn, F.; Gascon, J. Progress in developing a structure-activity relationship for the direct aromatization of Methane. ChemCatChem 2019, 11, 39-52. [CrossRef]

19. Gao, K.; Yang, J.; Seidel-Morgenstern, A.; Hamel, C. Methane dehydro-aromatization: Potential of a Mo/MCM-22 catalyst and hydrogene-selective membranes. Chem. Ing. Tech. 2016, 88, 168-176. [CrossRef]

20. Sun, C.; Yao, S.; Shen, W.; Lin, L. Hydrothermal post-synthesis of HMCM-49 to enhance the catalytic performance of the $\mathrm{Mo} / \mathrm{HMCM}-49$ catalyst for methane dehydroaromatization. Micropor. Mesopor. Mater. 2009, 122, 48-54. [CrossRef] 
21. Liu, H.; Yang, S.; Wu, S.; Shang, F.; Yu, X.; Xu, C.; Guan, J.; Kan, Q. Synthesis of Mo/TNU-9 catalyst and its catalytic performance in methane non-oxidative aromatization. Energy 2011, 36, 1582-1589. [CrossRef]

22. Shi, Y.; Xing, E.; Xie, W.; Zhang, F.; Mu, X.; Shu, X. Shape selectivity of beta and MCM-49 zeolites in liquid-phase alkylation of benzene with ethylene. J. Mol. Catal. A-Chem. 2016, 418, 86-94. [CrossRef]

23. Fransen, T.; van der Meer, O.; Mars, P. Investigation of the surface structure and activity of molybdenum oxide-containing catalysts: I. An infrared study of the surface structure of molybdena-alumina catalysts. J. Catal. 1976, 42, 79-86. [CrossRef]

24. Lu, Y.; Chen, W. Sub-nanometre sized metal clusters: From synthetic challenges to the unique property discoveries. Chem. Soc. Rev. 2012, 41, 3594-3623. [CrossRef] [PubMed]

25. Turner, M.; Golovko, V.B.; Vaughan, O.P.H.; Abdulkin, P.; Berenguer-Murcia, A.; Tikhov, M.S.; Johnson, B.F.G.; Lambert, R.M. Selective oxidation with dioxygen by gold nanoparticle catalysts derived from 55-atom clusters. Nature 2008, 454, 981-983. [CrossRef] [PubMed]

26. Chernova, N.A.; Roppolo, M.; Dillon, A.C.; Whittingham, M.S. Layered vanadium and molybdenum oxides: Batteries and electrochromics. J. Mater. Chem. 2009, 19, 2526-2552. [CrossRef]

27. Zhou, J.; Xu, N.S.; Deng, S.Z.; Chen, J.; She, J.C.; Wang, Z.L. Large-area nanowire arrays of molybdenum and molybdenum oxides: Synthesis and field emission properties. Adv. Mater. 2003, 15, 1835-1840. [CrossRef]

28. Konnov, S.V.; Dubray, F.; Clatworthy, E.B.; Kouvatas, C.; Gilson, J.-P.; Dath, J.-P.; Minoux, D.; Aquino, C.; Valtchev, V.; Moldovan, S.; et al. Novel. strategy for the synthesis of ultra-stable single-site Mo-ZSM-5 zeolite nanocrystals. Angew. Chem. Int. Ed. 2020, 59, 2-10.

29. Fernandes, C.I.; Capelli, S.C.; Vaz, P.D.; Nunes, C.D. Highly selective and recyclable $\mathrm{MoO}_{3}$ nanoparticles in epoxidation catalysis. Appl. Catal. A-Gen. 2015, 504, 344-350. [CrossRef]

30. Manivel, A.; Lee, G.-J.; Chen, C.-Y.; Chen, J.-H.; Ma, S.-H.; Horng, T.-L.; Wu, J.J. Synthesis of $\mathrm{MoO}_{3}$ nanoparticles for azo dye degradation by catalytic ozonation. Mater. Res. Bull. 2015, 62, 184-191. [CrossRef]

31. Turco, R.; Bonelli, B.; Armandi, M.; Spiridigliozzi, L.; Dell'Agli, G.; Deorsola, F.A.; Esposito, S.; Di Serio, M. Active and stable ceria-zirconia supported molybdenum oxide catalysts for cyclooctene epoxidation: Effect of the preparation procedure. Catal. Today 2020, 345, 201-212. [CrossRef]

32. Malcolmson, S.J.; Meek, S.J.; Sattely, E.S.; Schrock, R.R.; Hoveyda, A.H. Highly efficient molybdenum-based catalysts for enantioselective alkene metathesis. Nature 2008, 456, 933-937. [CrossRef]

33. Wang, J.; Wu, W.; Yang, Q.; Wang, W.-H.; Bao, M. Improving the stability of subnano-MoO $3 / \mathrm{meso}^{-S i O}$ catalyst through amino-functionalization. Funct. Mater. Lett. 2017, 11, 1850003. [CrossRef]

34. Wang, D.Y.; Kan, Q.B.; Xu, N.; Wu, P.; Wu, T.H. Study on methane aromatization over $\mathrm{MoO}_{3} / \mathrm{HMCM}^{-49}$ catalyst. Catal. Today 2004, 93, 75-80. [CrossRef]

35. Martínez, A.; Peris, E. Non-oxidative methane dehydroaromatization on Mo/HZSM-5 catalysts: Tuning the acidic and catalytic properties through partial exchange of zeolite protons with alkali and alkaline-earth cations. Appl. Catal. A-Gen. 2016, 515, 32-44. [CrossRef]

36. Xu, Y.; Liu, S.; Wang, L.; Xie, M.; Guo, X. Methane activation without using oxidants over Mo/HZSM-5 zeolite catalysts. Catal. Lett. 1995, 30, 135-149. [CrossRef]

37. Chen, L.Y.; Lin, L.W.; Xu, Z.S.; Li, X.S.; Zhang, T. Dehydro-oligomerization of methane to ethylene and aromatics over molybdenum/HZSM-5 catalyst. J. Catal. 1995, 157, 190-200. [CrossRef]

38. Yao, S.; Sun, C.; Li, J.; Gu, L.; Shen, W. Reaction coupling of methane steam reforming and methane dehydroaromatization for improving durability of Mo/MCM-49 catalyst. Chin. J. Catal. 2009, 30, 1022-1028. [CrossRef]

39. Rahman, M.; Infantes-Molina, A.; Boubnov, A.; Bare, S.R.; Stavitski, E.; Sridhar, A.; Khatib, S.J. Increasing the catalytic stability by optimizing the formation of zeolite-supported Mo carbide species ex situ for methane dehydroaromatization. J. Catal. 2019, 375, 314-328. [CrossRef]

40. Wu, Y.; Emdadi, L.; Schulman, E.; Shu, Y.; Tran, D.T.; Wang, X.; Liu, D. Overgrowth of lamellar silicalite-1 on MFI and BEA zeolites and its consequences on non-oxidative methane aromatization reaction. Micropor. Mesopor. Mater. 2018, 263, 1-10. [CrossRef]

41. Tan, P. The catalytic performance of Mo-impregnated HZSM-5 zeolite in $\mathrm{CH}_{4}$ aromatization: Strong influence of Mo loading and pretreatment conditions. Catal. Commun. 2018, 103, 101-104. [CrossRef]

42. Ramasubramanian, V.; Lienhard, D.J.; Ramsurn, H.; Price, G.L. Effect of addition of K, Rh and Fe over Mo/HZSM-5 on methane dehydroaromatization under non-oxidative conditions. Catal. Lett. 2019, 149, 950-964. [CrossRef] 
43. Guo, X.; Fang, G.; Li, G.; Ma, H.; Fan, H.; Yu, L.; Ma, C.; Wu, X.; Deng, D.; Wei, M.; et al. Direct, Non-oxidative conversion of methane to ethylene, aromatics, and hydrogen. Science 2014, 344, 616. [CrossRef] [PubMed]

44. Rahman, M.; Sridhar, A.; Khatib, S.J. Impact of the presence of Mo carbide species prepared ex situ in Mo/HZSM-5 on the catalytic properties in methane aromatization. Appl. Catal. A-Gen. 2018, 558, 67-80. [CrossRef]

45. Jarvis, J.; Wong, A.; He, P.; Li, Q.; Song, H. Catalytic aromatization of naphtha under methane environment: Effect of surface acidity and metal modification of HZSM-5. Fuel 2018, 223, 211-221. [CrossRef]

46. Hu, J.; Wu, S.; Ma, Y.; Yang, X.; Li, Z.; Liu, H.; Huo, Q.; Guan, J.; Kan, Q. Effect of the particle size of $\mathrm{MoO}_{3}$ on the catalytic activity of Mo/ZSM-5 in methane non-oxidative aromatization. New J. Chem. 2015, 39, 5459-5469. [CrossRef]

47. Sun, K.; Gong, W.; Gasem, K.; Adidharma, H.; Fan, M.; Chen, R. Catalytic methane dehydroaromatization with stable nano Fe doped on Mo/HZSM-5 synthesized with a simple andenvironmentallyfriendlymethod and clarification of a perplexing catalysis mechanism dilemma in yhis field for aperiod of time. Ind. Eng. Chem. Res. 2017, 56, 11398-11412. [CrossRef]

48. Liu, W.; Xu, Y. Methane dehydrogenation and aromatization over Mo/HZSM-5: In Situ FT-IR characterization of its acidity and the interaction between Mo species and HZSM-5. J. Catal. 1999, 185, 386-392. [CrossRef]

49. Fila, V.; Bernauer, M.; Bernauer, B.; Sobalik, Z. Effect of addition of a second metal in Mo/ZSM- 5 catalyst for methane aromatization reaction under elevated pressures. Catal. Today 2015, 256, 269-275. [CrossRef]

50. Tshabalala, T.E.; Coville, N.J.; Scurrell, M.S. Dehydroaromatization of methane over doped Pt/Mo/H-ZSM-5 zeolite catalysts: The promotional effect of tin. Appl. Catal. A-Gen. 2014, 485, 238-244. [CrossRef]

(C) 2020 by the authors. Licensee MDPI, Basel, Switzerland. This article is an open access article distributed under the terms and conditions of the Creative Commons Attribution (CC BY) license (http://creativecommons.org/licenses/by/4.0/). 